Cuadernos de Trabajo Social

ISSN-e: 1988-8295

https://doi.org/10.5209/cuts.65078

\title{
Locura, mujer y comunidad. Entrevista con Montserrat Castanyer
}

Mercedes Muriel Saiz*

\section{[en] Madness, woman and community. Interview with Montserrat Castanyer}

Montserrat Castanyer es una de las trabajadoras sociales que goza de un gran reconocimiento en el contexto nacional, pues su figura ha sido y sigue siendo fundamental en el desarrollo de la profesión en diferentes espacios, especialmente en aquellos vinculados a la salud mental. Desde muy joven supo que quería ser asistente social, y así se define ella. Lo de trabajadora social llegaría más tarde.

Nunca ha dejado de formarse, de aprender, de curiosear pero, desde luego, su paso por la Escuela de Lagasca, donde se formó como asistente social, hizo mella en su trayectoria profesional y en su desarrollo posterior, especialmente con sus prácticas de segundo curso donde tuvo su primer contacto con la locura, y se dijo a sí misma, "no les podemos tratar as'́". Se comprometió a cambiar la atención social de las personas con enfermedad mental y, desde luego, lo consiguió. A su vez, siempre ha tenido presente dos perspectivas complementarias que han ido guiando su tarea profesional, su ser y hacer Trabajo Social: la dimensión comunitaria de la intervención social y la mirada de género en sus acciones profesionales (y personales).

También ha transitado por diferentes contextos del Trabajo Social. Ha estado vinculada al ámbito académico, encargándose durante años de la gestión de las prácticas de las estudiantes de la Escuela Oficial de Asistentes Sociales de Madrid. Pero a diferencia de otras trayectorias profesionales, ella decidió apostar por continuar desarrollando su labor en el mundo profesional aunque sin desvincularse del todo del mundo académico. Actualmente es parte integrante del Equipo Editorial de la revista Cuadernos de Trabajo Social y parte activa del Observatorio de la Exclusión Social y de los Procesos de Inclusión de la Comunidad de Madrid (OEISM).

Pensar en Montserrat Castanyer es también pensar en el Instituto de Trabajo Social y Servicios Sociales (INTRESS); en una carrera profesional sustentada por un compromiso ético, político y social; en una dedicación continua en la búsqueda de una intervención social novedosa, reflexionada y, sobre todo, una intervención social capaz de romper la barrera de lo individual, grupal y comunitario, una intervención social holística.

Antes de comenzar esta entrevista sobre tus reflexiones acerca de tu trayectoria profesional como trabajadora social, te quería dar las gracias por aceptar esta entrevista y por tu compromiso continúo con Cuadernos de Trabajo Social. Si te parece bien, vamos a empezar esta conversación hablando un poco de tu formación. ¿Por qué elegiste ser asistente social?

Bueno, a ver... la idea de ser asistente social la tengo desde los quince años y es una idea fija. Esto me lo han preguntado más veces, ¿por qué asistente social? Pues creo que fue a partir de la lectura de un libro que se titulaba Perros perdidos sin collar que me impactó muchísimo. Desde que lo leí, dije que quería ser eso y ya está. Entonces cuando tenía quince años terminé el Bachillerato de aquel entonces e hice el Preuniversitario que lo terminé con dieciséis. En ese momento, busqué dónde estudiar asistencia social. Yo era muy autogestionada, mi familia era muy de darte soporte, de acompañarte, de darte alas, pero todo lo que tú 
pudieras hacer, lo hacías. Entonces no sé cómo llegué a la Escuela de Lagasca, te estoy hablando del año 61, quizás... o el año 60. Entonces, al terminar Preuniversitario, fui a hacer una entrevista en aquella escuela. A esa entrevista sí que me acompaño mi madre, y me dijeron que no lo podía hacer porque no admitían estudiantes hasta los dieciocho años. ¡Imagínate el disgusto! Me cogí un disgusto de muchísimo cuidado. Como no lo podía hacer, me dijeron que volviera cuando tuviera dieciocho años. Recuerdo aquello como el disgusto en mi casa también porque, imagínate, yo tan jovencita... y entonces recuerdo que mi padre me dijo que no veía problema, que hiciera Filosofía y Letras o que hiciera Medicina. Él me preguntaba: ¿Tú que quieres hacer? Puedes hacer lo que quieras ser. Nada, yo quería ser asistente social, así que me busqué otras cosas que hacer en ese tiempo hasta tener los dieciocho. Me fui un tiempo a Francia, allí aprendí muchísimas cosas y en cuanto cumplí los dieciocho volví a la Escuela de Lagasca. Allí que me presenté y dije "pues nada, aquí estoy, ya tengo dieciocho". Ya me pudieron matricular y comencé mis estudios de asistente social.

Lo de ser asistente social era una idea fija. $Y$ ahora tengo una nieta que está pensando qué puede estudiar, está en ese momento vital de la inquietud universitaria y hace poco me preguntó esto mismo: ¿y tú por qué quisiste ser asistente social? Y le conté la historia del libro de Perros perdidos sin collar y le presté el libro, que lo seguía teniendo de aquel entonces. Bueno antes de dárselo, lo leí un poco por si decía cosas que no... pero mira que han pasado años y releyéndolo me di cuenta del porqué de ser asistente social. En este momento lo que cuenta ese libro tiene corresponde en la actualidad con los menores no acompañados, que están en la calle...

Es muy bonito escucharte y ver cómo has tenido siempre muy claro que querías ser asistente social.

Sí, y esos comienzos que empecé como asistente social es algo que me ha marcado. Yo siempre me presento como asistente social, aunque luego haya hecho otras cosas, he sido y soy asistente social y luego trabajadora social. Lo que me define como profesión y también como persona es el ser asistente social. Y eso que no existían los estudios que hay ahora, los estudios no estaban reconocidos, era una profesión que no estaba reconocida. Yo me examiné el último año antes de que empezaran a hacerse los exámenes en lo que luego se convirtió en Escuela Oficial de Asistentes Sociales, en 1965.

¿Qué interesante! Te quería preguntar sobre las prácticas curriculares, te pregunto por ellas porque hace algunos años que te escuché en una charla en la Facultad hablar de cómo te habian marcado las prácticas en tu desarrollo profesional posterior.

Pues el primer año, porque entonces las prácticas eran todos los años, las hice en una parroquia en Villa de Vallecas. Yo sabía que había un cura de mi colegio que vivía con el Padre Llanos en El Pozo, y no sé por qué el caso es que fui a parar a esa parroquia para mis prácticas del primer año. Tuve la oportunidad de conocer el contexto de Villa de Vallecas, aunque, bueno, yo creo que era como muy inocente todo, muy cercano y familiar ¿sabes? Luego en el segundo año, fueron las prácticas que más me marcaron, las hice en el Servicio de Psiquiatría del Hospital Provincial de entonces, que ahora es el actual Museo Reina Sofía. Todavía ahora, cuando entro, me lleva a esos años, me transporto a aquellos recuerdos y cada vez que entro me da un vuelco el estómago porque esa fue una experiencia impactante para mí. Fue mi primer contacto con la locura, una locura que luego me ha marcado toda la vida. El primer contacto con la locura en un contexto de encierro. Tú imagínate con lo joven que era yo... que me dieron una bata blanca para que no me confundieran con una loca, también me dieron un llavín para entrar y salir de las habitaciones... Yo que me vi con eso, dije "ostras, esto es muy serio" y creo que ahí todavía no era tan consciente de lo que veía, pero ya empezaba a sentir una especie de rebelión de que eso no puede ser, no podemos tratar así a esas personas. Fueron unas prácticas muy enriquecedoras, aprendí muchísimas cosas y terminé esa etapa pensando: "no los podemos tratar as'i", y ese pensamiento ha marcado mi trayectoria profesional.

En el tercer año hice las prácticas en el Tribunal Tutelar de Menores que, en teoría, era por lo que yo había empezado a estudiar para asistente social, aquello del libro que te contaba antes... pero cuando llegué allí me encontré con que el Tribunal Tutelar de Menores era una institución obsoleta, era un jaleo, un guirigay tremendo, muy marcado por la opinión del juez. Allí los delegados de vigilancia no pintábamos nada y realmente no me dieron ganas de vincularme a eso, pero tampoco sentí que tuviera la oportunidad. 
Estas fueron mis prácticas, ¿cuál es la que más me impactó? Las de segundo curso en el Psiquiátrico del Hospital Provincial. Me impactó muchísimo; luego he vuelto sobre esa experiencia muchas veces porque era realmente atrapante, era algo que veías que no podía ser, que como asistente social no podía mirar a otro lado.

Tras tus estudios de asistencia social, ¿cómo fue tu inserción en el mundo profesional? Me genera curiosidad conocer los primeros pasos profesionales de una profesional de referencia en el mundo del Trabajo Social.

Yo terminé los estudios en el año 1965 y, bueno, en el 1965 el desarrollo de Servicios Sociales era nulo, inexistente casi. Había contrataciones de asistentes sociales en determinadas instituciones y a nivel público, por ejemplo, el Ayuntamiento de Madrid tenía una dotación de asistentes sociales en algunos distritos, no en todos porque no había un departamento como tal, había asistentes sociales adscritas a otros departamentos. Y la verdad es que por ahí a mí no me salió ni me llegó trabajo, pero en aquel entonces alguien me propuso contratarme en una organización, que se llamaba OCASEI, era la Obra Católica de Atención a Estudiantes Iberoamericanos, que dependía de la Iglesia. El objetivo era dar acogida y atención a los estudiantes de países latinoamericanos, entonces se llamaban de Iberoamérica, que venían a estudiar a España. En este sentido, el objetivo principal era que estuvieran acogidos, que tuvieran un sitio al que poder acudir si les pasaba algo. Además, también tenía como objetivos fomentar que no se quedasen demasiado tiempo en España tras finalizar sus estudios; digamos que lo que había en el trasfondo de esa organización era acogerlos pero no acogerlos para que se quedaran. Bueno, si se querían quedar podían hacerlo, pero la idea era el acompañamiento con una perspectiva de retorno porque venían de países que habían hecho un esfuerzo muy alto a nivel educativo, haciendo una apuesta por el retorno del talento como elemento fundamental. Ese fue mi primer trabajo, recuerdo que las oficinas estaban detrás de Correos, detrás de lo que ahora es el Ayuntamiento de Madrid, y la verdad que fue una experiencia interesante porque conocía a gente de muchos países. Me vinculó a una realidad desconocida porque no tenía nada que ver con las prácticas de los estudios que fueron en otros espacios de atención. Como ves, aproveché la primera opción laboral que tuve al terminar los estudios porque lo que he tenido siempre muy claro era que yo tenía que ser autónoma, una mujer independiente, ganar mi dinero para vivir.

Después de OCASEI, me contrataron y me empezaron a encargar funciones similares pero en una organización a nivel europeo que hacía lo mismo. Esta organización era como la sede europea de lo que te comentaba antes de la acogida a estudiantes iberoamericanos, tenía sede en Suiza y en Bruselas con el mismo objetivo fundamental. Así que pasé de ocuparme de los estudiantes iberoamericanos en Madrid, en Bilbao, en Barcelona, en distintos sitios donde había focos de estudiantes, a empezar a ocuparme de estudiantes en Bruselas. Fue un momento muy interesante porque empecé a contactar con otras universidades belgas, por ejemplo en Lovaina. La verdad es que eso de ir y venir en el tren, de pasar por París, y luego seguir a Bruselas, para una chica jovencita fue una oportunidad estupenda. Lo recuerdo como una experiencia magnífica. Es verdad que en este nuevo trabajo en Bruselas, ya no tenía un contacto tan directo con los estudiantes, sobre todo trabajaba con las universidades que los acogían.

Con esta experiencia europea podemos decir que empieza a despertar la mirada internacional que te ha acompañado profesionalmente a lo largo de tu vida...

Sí, de hecho, el paso de OCASEI a la europea fue como un paso distinto que me ayudó a mirar fuera de España, porque esos años aquí eran muy turbios, eran muy negros por la situación política que vivíamos. En el momento yo no los veía tan oscuros, pero sí que lo eran. Estábamos en una dictadura aunque poco a poco ya bullían movimientos con un compromiso de buscar otras vías ante situaciones sociales que no considerábamos justas. Entonces, entre mis viajes a Bruselas y mis estancias en Madrid, ¿qué pasó? Pues que me enamoré y, entre medias, me casé. Ya había dado el paso a Europa, así que nos fuimos a vivir a Londres y tuve la suerte de que puse seguir haciendo ese trabajo desde Inglaterra. Allí estuvimos dos años y medio (1969-1971), con este trabajo que era muy liviano y me permitía ir a Oxford, Cambridge, Liverpool, y como no sabía todavía muy bien inglés, el hecho de tener que hablar en el trabajo con personas latinoamericanas pues tampoco me ayudó mucho, pero al final aprendes la lengua. De mis años en Londres, tengo que contarte que tuve la oportunidad de conectar los estu- 
dios de asistencia social con todo el tema de la intervención comunitaria. En mi paso por los estudios de asistente social, tuve dos profesoras que me marcaron... de esas profesoras que te dicen cosas que te guardas para siempre. Una de ellas fue Raquel Payá, que ya falleció, que me enseñó Psicología y recuerdo sus clases como algo espléndido; luego en tercer año de carrera en Madrid, tuve una asignatura que se llamaba Desarrollo comunitario y recuerdo que me impactó. Aprendí muchísimo y disfruté otro tanto. Esta asignatura me abrió una ventana para llegar a entender que no se podía intervenir solo con la persona, sino que había que tener en cuenta también su contexto y sus relaciones. Recuerdo que la profesora se llamaba Pilar Pérez Iturbe. Esto del desarrollo comunitario me marcó porque yo había estudiando la atención individual, la grupal y lo comunitario, pero fue realmente en Inglaterra cuando pude conectar lo que había aprendido de la comunidad. Como ya sabía un poquito más de inglés, encontré un Instituto adscrito al London School of Economics que era maravilloso, allí aprendí cosas que no había escuchado antes. Me apunté a un curso que se llamaba Community Action, aprendí mucho sobre experiencias a nivel comunitario. Recuerdo que, además, iba a veces con mi hija en la mochila a clase, porque yo quería seguir formándome, el proyecto era lo importante, el proyecto vital, lo profesional y lo personal.

A lo largo de tu narración parece que se van conectando las ideas que han acompañado tu proyecto: la salud mental, lo comunitario y el género...

La salud mental, por una parte, también el feminismo porque cuando no se hablaba de feminismo en ninguna parte, ya había mujeres que estábamos llevando una práctica feminista vital y, por supuesto, la perspectiva comunitaria. Te intercalo porque cuando acabé los estudios de asistente social y empecé a trabajar en OCASEI, como eran solo unas horas podía seguir formándome y busqué dónde complementar lo que había aprendido en la carrera. Busqué dos cosas que fueron complementarias. Por un lado, la Escuela de Psicología. En ese momento no había Facultad de Psicología, había una escuela de psicología aneja a la Universidad Complutense, con los grandes popes de los que formaron luego la Facultad. Lo que pasaba es que para apuntarte tenías que ser licenciada, pero como yo no lo era porque tenía lo de asistente social, pues fui y se lo conté y aunque no me iban a dar el título, me dejaron ir de oyente y yo pensé: “iQué bien! Si a mí los títulos no me importan". Te cuento esto de los títulos, porque ha sido una tónica general en mi vida. Voy a pensar contigo en alto un poco, y fíjate que a veces pienso "pues a lo mejor no tenías que ser así', pero bueno: he sido así y esa ha sido mi tónica. Entonces hice los dos cursos de Psicología, y creo que aprendí muchas cosas porque era como que te haces asistente social y te faltan cosas para entender, te faltan cosas para entender a la persona. Después de esta formación, sentía que luego me faltaban cosas para entender a la sociedad, así que como tampoco había Sociología en la Universidad, me apunté a una formación que era muy de ese momento y que después se perdió. Sucedió que expedientaron a unos profesores, a Tierno Galván, a Aranguren y se montó una cosa que era la Escuela Crítica de Ciencias Sociales y estaban lo bueno y mejor de todo y de cada casa. Lo bueno y mejor de todo no solo de los alumnos sino también de los profesores. Aquello era interesantísimo, había todo un movimiento de vinculación con partidos de izquierda, muy de izquierda... Empezaban las reivindicaciones con el trabajo vecinal en los barrios, en Madrid con las UVAS (Unidad Vecinal de Absorción), por ejemplo. Fue un tiempo muy bonito, hasta que la Escuela la cerraron, difícilmente el Franquismo podía tolerar una Escuela como esa.

Coincidió que volví de Londres y me puse a buscar trabajo pero, claro, en aquellos años era una mujer con un embarazo incipiente y me preguntaban en las entrevistas si iba a tener más hijos. De esas me llevé unas cuantas, pero como soy de poco desesperarme con las situaciones porque si no se puede hacer una cosa ya saldrá otra, presenté al Ayuntamiento de Madrid un proyecto comunitario muy bonito que traía de Londres, que se llamaba Adventures Playgrounds para aprovechar solares vacíos y montar lugares de juego libre. Aquello producía cohesión entre las personas y una oportunidad de crecimiento comunitario, pero nada. Tampoco tuvo éxito ese proyecto porque, aunque ahora sí que hay muchas iniciativas de esas como el CRPS de Vallecas con la asociación de vecinos, en aquel entonces era una idea que yo traía del contexto inglés y que no lo terminaban de entender. Han pasado más de cuarenta años y ahora veo iniciativas parecidas en barrios de Madrid. Así que mientras encontraba trabajo, me apunté a la carrera de Ciencias Políticas. 
Aquellos fueron unos años estupendos, leía textos muy interesantes y aprendí mucho. Finalmente lo tuve que dejar porque encontré trabajo y no podía compaginarlo, pero ahora con los años atrás lo pienso y digo, ¡qué suerte tuve! A lo largo de mi vida he ido tomando decisiones que me hacían sentir bien, es un privilegio porque he ido siempre apostando en mi vida por aquellas opciones más estimulantes, interesantes.

Decías que como te incorporaste a trabajar nuevamente, tuviste que dejar la carrera de Ciencias Políticas. ¿Dónde empezaste a trabajar?

Sí, empecé a trabajar en el Gran Hospital de Diego de León que es ahora el Hospital de La Princesa. Me contrataron como asistente social en la Escuela de Administración Hospitalaria que tenía un Servicio de Salud Mental y es en ese momento cuando aquel primer contacto que tuve con la locura empieza a tomar forma, profesionalmente hablando. Es como si la vida me hubiera ido llevando al tema de la locura porque mi gran pasión son las personas con enfermedad mental, los locos, y que estas personas vivan de otra manera. Además, en este momento empecé a trabajar en la Escuela Oficial de Trabajadores Sociales coordinando las prácticas. Pienso que era más fácil que ahora porque aunque había prácticas los tres cursos, eran muchas menos alumnas y de aquella experiencia lo que más me gustó fue la relación con las alumnas. Más adelante, del Hospital pasé a la AISNA (Administración Institucional de la Sanidad Nacional) porque saqué unas oposiciones de asistente social, a las que luego renuncié, por mi "aprecio" a los títulos de que antes hablábamos. En aquel entonces se creó el Centro de Salud Mental Universidad que fue un embrión de lo que ahora conocemos como los centros de salud mental, era algo totalmente novedoso porque en Madrid no había ninguno. Tuve la oportunidad de estar en aquellos comienzos junto con el psiquiatra que impulsó todo aquello, trabajando en coordinación en un equipo multidisciplinar con psiquiatras, enfermeras, psicólogos, asistentes sociales y la administrativa. Era un grupo de trabajo muy bueno, fue un momento de mucho aprendizaje, con visiones complementarias sobre qué hacer y cómo hacer, aplicando la perspectiva comunitaria, nos animamos a hacer charlas sobre salud mental en diferentes contextos. En ese momento se estaba dando en España, por una parte, el movimiento de la Antipsiquiatría.
Desde Italia venía F. Basaglia y las profesionales de la salud en las que también participábamos asistentes sociales, se organizaban en contestación a la psiquiatría imperante. Además, por otra parte, las primeras asociaciones de familiares de personas con enfermedad mental con un carácter muy reivindicativo, que iniciaban experiencias alternativas como Nueva Vida que fue la primera que hubo en Madrid, con la que me vinculé mucho.

Aquí sí me gustaría contarte que, en el Centro de Salud Mental Universidad junto con una compañera junto con una compañera, psicóloga, pusimos en marcha una experiencia única hasta el momento que fue crear un grupo de mujeres, llevado por mujeres y solo para mujeres. Eso fue una experiencia preciosa, el efecto terapéutico de los grupos se multiplicaba, se respiraba el tema del género porque las mujeres hablaban entre ellas con total libertad. Fue muy bonito. Recuerdo aquella etapa con mucho cariño, pero finalmente me cambié porque mi jefe me comentó que estaban poniendo en marcha el Instituto de la Salud Mental, en la entonces Diputación Provincial de Madrid. Aquello fue el embrión de lo que más tarde sería la Consejería de Sanidad y Bienestar Social de Comunidad de Madrid. Aquel equipo lo formaban psiquiatras y dos trabajadoras sociales, y la verdad que yo, como trabajadora social, siempre me sentí muy reconocida, sentía que mi opinión era considerada. Es verdad que los psiquiatras siempre están más valorados, pero les interesaba mi opinión, mi perspectiva porque era diferente a la de ellos, yo tenía en cuenta el contexto de las personas. Fueron unos años muy enriquecedores, pude trabajar por revertir aquello que vi en mis prácticas de segundo. Era muy emocionante porque había que poner en marcha una atención diferente a la ofrecida hasta el momento, que se fue asentando con la consolidación de la Reforma Psiquiátrica en Madrid. Fueron años de poner en marcha todo el sistema de atención a la salud mental de Madrid, fuimos montando los centros de cada distrito, negociando también con la Seguridad Social. Recuerdo que montamos el Primer Plan de Salud Mental de la Comunidad de Madrid, ahora me parece rudimentario porque había pocos datos contrastables, pero sentaba las bases de atención en la comunidad, siempre trabajando con la idea de integrar una red de atención en salud mental. Sin embargo, con la llegada del gobierno socialista dijeron que iban a ir eliminando el funcionariado, así 
que ya sabes que no he sentido nunca mucho apego por los títulos y decidí renunciar a mi puesto de funcionaria porque pensé, "estoy de acuerdo que se contrate laboralmente a las personas", y así es como dejé de ser funcionaria en el ámbito de salud.

¿Cómo fue tu salida tras tanto tiempo trabajando en la creación de una red pública de atención a la salud mental?

Lo que pasó fue que empezamos a plantear propuestas novedosas en la intervención a personas con enfermedad mental, la creación de recursos de soporte social como podía ser la Casa de Transición y otros.Todo esto se veía con desconfianza y con escaso apoyo para implementarlo por parte de algunos responsables administrativos. También fue decisivo que el empeño por conseguir que el personal que se integraba en los nuevos Centros de Salud Mental tuviera las mismas condiciones salariales y laborales y que no se mantuvieran situaciones de privilegio fue para mí una lucha fracasada. La Consejería se estaba burocratizando y determinados planteamientos de cambios no eran escuchados. Así que como no tenía ganas de irme todos los días enfadada a casa y además sentía que había cumplido el objetivo en el que durante años trabajé (que hubiera un Centro de Salud Mental en cada zona de la Comunidad de Madrid) opté por comunicarle al consejero mi marcha. Aunque los añoro, sigo vinculada al colectivo de profesionales de la Salud mental, creo que personalmente tome la opción que me iba a permitir seguir creciendo personal y profesionalmente.

Supongo que te imaginarás que voy a preguntarte por INTRESS, acerca de cuándo comienza tu vinculación con esta entidad. Al conversar sobre tu trayectoria profesional, no podemos perder de vista la idea de que pensar en ti es también pensar de alguna manera en INTRESS.

Mi origen es catalán, pero me vine a vivir a Madrid, contra mi voluntad, cuando tenía trece años con mi familia, por eso me formé en Madrid. Como soy un ser adaptativo, pues me adapté muy bien, pero siempre he mirado hacia Cataluña y he estado vinculada con lo que sucedía allí en torno a las asistentes sociales. Desde sus inicios he sido lectora de la Revista de Treball Social, la revista del Colegio de Trabajo Social de Barcelona de la que sigo aprendiendo. Fui a una escuela de verano en Barcelona que organizó GRITS (Grupo de Investigación en Trabajo Social) al estilo de la
Escuela de Educación Rosa Sensat, y allí conecté y conocí a una serie de personas que luego montaron INTRESS. Montserrat Colomer, Rosa Domenech, Gloria Rubiol, son la generación que están por encima de mí y que en ese momento estaban entrando a montar los departamentos de servicios sociales del Ayuntamiento de Barcelona. Era el tiempo de los primeros ayuntamientos democráticos. En 1983 crearon INTRESS y de manera informal, en una de sus visitas a Madrid, Gloria Rubiol me propone asociarme a INTRESS. La verdad es que la idea me gustó mucho porque eran mujeres y trabajadoras sociales, eso ya me parecía fantástico así que me asocié. Montaban jornadas, generaban debates, reflexionaban en torno a la profesionalización de las trabajadoras sociales en los incipientes Servicios Sociales. En sus inicios buscaban mejorar la formación de las profesionales que tenían que empezar a intervenir en un sistema novedoso que se estaba generando. $\mathrm{Y}$ en esos comienzos estaba lejos de la gestión de servicios como tal, por la que desde hace tiempo se nos viene conociendo. Así me vinculé a INTRESS pero también al Col.legi Oficial de Treball Social de Catalunya y a la RTS (Revista de Treball Social).

Coincidió con que dejé la Consejería de Sanidad y Bienestar Social de la Comunidad de Madrid y como había dado algún curso de formación en INTRESS sobre salud mental y Trabajo Social, me fui vinculando cada vez más. La idea de la formación inicial de la que se ocupaba INTRESS fue cambiando con un encargo concreto del Ayuntamiento de Barcelona que les propone poner en marcha un servicio. La titularidad seguía siendo del Ayuntamiento pero la gestión dependía de INTRESS porque en la Administración no sabían cómo ponerlo en marcha. Se trataba de dar respuesta a las urgencias infantiles, por ejemplo cuando una madre desaparece o hay una situación de conflicto familiar y los menores se quedan desprotegidos. Era atender esa primera urgencia con los menores. Se trataba de dar respuesta a un encargo concreto de la Administración para ver si funcionaba ese servicio y se podía institucionalizar y así es como se empiezan los convenios de colaboración o las contrataciones de servicios. O sea que por ahí empieza la andadura de INTRESS en cuanto a la gestión de servicios. Además, ese servicio sigue en la actualidad funcionando financiado por varias administraciones. 

drid?

¿Cómo llega INTRESS a instalarse en Ma-

Pues aunque en un principio no había una idea de montar una sede en Madrid, en 1990 Rosa Domenech, presidenta de Intress, me propuso poner en marcha la sede de INTRESS en Madrid. En ese momento a mí ni se me pasaba por la cabeza porque no había dinero para eso, pero me lo propusieron explicándome que todavía no había dinero y que tenía que encargarme de buscar la financiación. Y yo les dije que sí. Así que empezamos aquí en Madrid, una secretaria y yo. Continuamos con la formación para profesionales del Trabajo Social. Recuerdo una formación sobre la supervisión profesional en Servicios Sociales. Venía a dar esta formación una mujer argentina que era trabajadora social en Israel, especialista en Supervisión como herramienta de gestión en Servicios Sociales. Hicimos muchas ediciones de este curso, y la verdad es que lo recuerdo como una época también muy buena. Al final era sobre nuestro saber hacer, y fuimos por todos los distritos de Madrid, pero como no se continuó, tampoco sirvió de mucho. Fíjate si no han pasado años y todavía hay gente que me dice que recuerda como muy bueno aquellas sesiones de supervisión. La supervisión es un elemento básico en el desarrollo profesional.

En esas estábamos, empezando en Madrid, cuando la Consejería de Bienestar Social hace una convocatoria pública para la gestión de los centros de rehabilitación psicosocial (CRPS) para personas con enfermedad mental grave y duradera, que en aquel entonces era algo totalmente novedoso. Lo que es la vida que, cuando yo estaba allí en la Consejería de Sanidad en el Servicios de Salud Mental, junto con mi otra compañera trabajadora social también, tuvimos siempre muy claro que había que destinar un presupuesto importante a un tipo de atención que llamábamos "desarrollo de servicios alternativos a la institucionalización". Decíamos que para que la Reforma psiquiátrica funcionara adecuadamente, debía apoyarse en dos pilares:el de salud y el de Servicios Sociales. Nuestra idea apostaba más por centros de día o pisos tutelados. El caso es que la Consejería de Bienestar Social, que se había separado de la de Sanidad, apostó por este tipo de servicio. Y cómo es la vida, que como no lo podía hacer desde el Capítulo $1^{2}$, lo organizaron para ha-

En los presupuestos el Capítulo 1 es el destino a gastos de personal. cerlo por contratación de servicio público. Así que sacaron a concurso una propuesta que pensé junto con otras compañeras cuando estaba en la Consejería en Comunidad de Madrid. La nueva Consejería apostó por la creación de Centros de Rehabilitación Psicosocial dedicados a personas con enfermedad mental crónica. Como se trataba de un servicio totalmente nuevo del que no se sabía el resultado que iba a tener, optaron por la Convocatoria de contratos de gestión de servicio público. Así fue como se inició la puesta en marcha de estos Centros.

A la primera convocatoria no nos presentamos porque en ese momento se me planteaba el dilema de la gestión privada de un centro público. A lo largo de la vida profesional son varios los dilemas que te planteas. Hasta que pensé y lo debatí con mis compañeras de INTRESS, alguien lo tiene que hacer, alguien tiene que gestionar estos centros, así que pensé lo vamos a intentar, porque alguien lo tiene que hacer y lo vamos a hacer bien. Así fue como INTRESS en Madrid se presentó a una convocatoria para gestionar el centro de Los Cármenes en Carabanchel. Busqué ayuda en una persona que sabía mucho sobre la preparación de proyectos, montamos el equipo profesional y nos lo dieron. Fue tremendamente estimulante porque conectaba también con mi paso por Comunidad de Madrid, aquello de los centros de rehabilitación era una propuesta que habíamos sacado adelante con las complicidades de muchas personas y con mucha ilusión. El local que la Comunidad de Madrid nos cedió para el CRPS de Los Cármenes era el lugar perfecto porque, aunque eran unas instalaciones muy precarias físicamente, desde la óptica comunitaria, era un centro del barrio al que iban las mujeres a hacer gimnasia, los ancianos a la asociación de personas mayores, los jóvenes a otras cosas, y también por allí iban las personas con enfermedad mental; y eso para mí es un centro comunitario de verdad, porque nadie les preguntaba quiénes eran, a qué iban. Se entendía que iban a alguna actividad de allí. Fue muy bonito poner en marcha todo aquello, pero es verdad que la Administración nos renovaba cada año y así vuelta a empezar. Bueno, no sé si la palabra es exactamente bonita, pero fue un momento donde coincidimos Administración pública con las entidades privadas que nos ocupábamos de atender y dio lugar a muchas complicidades que, junto con el desempeño y dedicación de un colectivo de mag- 
níficos profesionales, han consolidado y han hecho crecer la red de servicios que actualmente existe en la Comunidad de Madrid.

¿Cómo viviste el paso de estar vinculada a la Administración pública a la entidad privada? Antes comentabas que tuviste algunos momentos con dilemas por este motivo.

Yo siempre he tenido una actitud de servicio y vocación a lo público y la sigo teniendo porque la ha tenido a lo largo de todo este tiempo que he estado tanto en la Administración como en INTRESS. Me gusta la idea de que haya entidades que podamos contribuir a gestionar servicios de manera adecuada; en el caso de INTRESS además es una fórmula jurídica sin ánimo de lucro. Por ejemplo, los centros de rehabilitación sin la participación de entidades privadas que se coordinaban con la Administración tal vez no hubieran salido o hubieran salido de otra manera. Me gusta pensar que contribuimos a eso, y ese para mí fue el paso de dejar de ser funcionaria contratada por la Administración a ser gestora o promotora de una entidad privada en la que también puedes ofrecer un sistema de calidad en la Administración, siempre tratando de generar un servicio lo mejor posible.

Dentro de las entidades privadas tal vez convendría diferenciar porque INTRESS tiene ámbitos de intervención especificos y no se presenta a cualquier pliego, sino que se identifica con determinados contextos de intervención. En Madrid, por ejemplo, se asocia sobre todo al ámbito de intervención de la salud mental y el género. Tal vez el riesgo y la demonización de la intervención social, gestionada por lo privado, pase por aquellas entidades que se presentan a cualquier pliego sin detenerse a pensar si esa problemática es su especialidad o tienen equipos profesionales suficientemente capacitados para desarrollar ese trabajo.

Sí. Totalmente. Eso nos ha hecho mucho daño a INTRESS como también nos ha hecho mucho daño la irrupción de empresas que no son del sector social y que tienen detrás a "fondos buitres". En este sentido tenemos ejemplos muy recientes, eso es algo terrible. A mí, eso me parece que es una involución terrible y es que es la lógica del mercado adentrándose en lo social en una sociedad capitalista. Pero ¿sabes qué pasa? Creo que la defensa de lo público no se hace solo desde el ámbito público, también se puede defender un tipo determinado de política social y una concepción de la sociedad donde se contemplen diferentes inter- vinientes. En el Trabajo Social, y en la acción social en general, hay muchas realidades que ahora están institucionalizadas, pero en sus orígenes surgieron de movimientos sociales como, por ejemplo, los familiares de niños con Síndrome de Down o las asociaciones de familiares de menores con enfermedades raras. Ahora son organizaciones que están institucionalizadas y este tipo de iniciativas de lo social también habla de la capacidad que tiene una sociedad para generar iniciativas. Es la búsqueda de la garantía de unos servicios públicos, pero teniendo en cuenta que el mundo cambia muchísimo y que hay otras maneras de hacer que se pueden probar y puede que tengan cabida. La iniciativa ciudadana y las organizaciones sociales tienen mucho que decir y han de ser escuchadas y tenidas en cuenta.

Esto que te cuento muchas veces no lo entiende el sector público, se trata de trabajar todas en la misma dirección por un servicio de calidad. Muchas trabajadoras sociales durante años han mirado con recelo a lo privado, pero yo siempre pienso "vamos a sentarnos y vamos qué es lo que tú haces, qué es lo que yo hago y juntas vamos a contribuir". INTRESS gestiona servicios públicos, se siente responsable de esta gestión y la Administración tiene que garantizar el presupuesto, el control de los gastos, el control de la acción, que las personas que accedan a ese servicio lo hagan de manera pública. Eso es fundamental, que la población destinataria de esos servicios llegue desde un acceso público. Podemos discutir sobre cómo hacerlo mejor y cómo hacerlo complementario.

El riesgo está cuando un sector crece y empiezan a irrumpir otras empresas que no son del sector. Ahora lo social es objeto de codicia, de deseo, de entidades que tienen gran diversificación de servicios, pueden hacer desde servicios sociales hasta dedicarse a la limpieza industrial de grandes superficies. Lo social era un sector que no tenía ninguna relevancia y ahora lo ven como algo rentable. Además también está la Ley de Contratos de la Administraciones Públicas que ha situado que esa fórmula es tan lícita como cualquier otra, y al final acaba primando el precio. Nosotras, desde INTRESS, siempre hemos valorado el proyecto, el equipo profesional, el servicio prestado frente a la primacía del precio, que es lo que se lleva ahora y muchas veces nos deja fuera del juego. Te voy a contar un ejemplo sangrante de esto. ¿Conoces el CIASI? 
Sí, el CIASI es un centro especializado para intervenir en casos de abusos sexuales a menores ¿no? Lo conozco de cuando estuve de prácticas en Servicios Sociales de Alcorcón.

Hace tiempo nos comentaron que tenían esta problemática y que en la Administración querían dar respuesta, así que nos propusieron a INTRESS poner en marcha un centro para intervenir con estos casos. Evidentemente es un tema muy delicado y había que garantizar el acceso libre, la confidencialidad, la profesionalidad. No era nuestra especialidad, pero tampoco era la especialidad de nadie en aquel entonces, así que montamos un equipo y nos presentamos al concurso. Estuvimos más de un año buscando profesionales expertas en el tema para montar el equipo, también teníamos que buscar el espacio físico, así que alquilamos el piso que estaba contiguo a nuestras oficinas. Bueno... pues ganamos el concurso y pusimos en marcha un centro que tardó un tiempo hasta que se fue asentando y nos comenzaban a llegar las derivaciones. Todo esto fue un proceso muy largo y a los cuatro años tenían que renovar el concurso nuevamente. Se presentaron algunas entidades porque el CIASI ya era un recurso conocido, con cierto nombre y de todas las entidades que se presentaron a la gestión del concurso, sucedió que INTRESS tenía mayor puntuación en la valoración del proyecto técnico y menor en la valoración en las clausulas económicas. La otra entidad al revés, ¿y qué pasó? Que perdió INTRESS porque no se valoró como más importante el proyecto técnico que era un equipo de profesionales expertos en el tema. Hubo que despedir al equipo, un tiempo de preparación del nuevo equipo, también de ir reorganizando las derivaciones, etcétera. Te quiero contar con esto, que creo que ahora están volviendo a valorar lo técnico, pero hemos tenido unos años muy fuertes con el tema de las contrataciones públicas y la primacía económica.

Algo así nos pasó también con el CENYF, que era un centro para valorar las derivaciones sobre tutelas de menores, cuando es un caso complejo que la intervención requiere de un equipo especialista. Como teníamos la experiencia de un centro similar en Cataluña, que lo sigue teniendo INTRESS y, como nadie lo había hecho hasta el momento en Madrid, nos ofrecieron presentarnos a un concurso y lo ganamos. Pusimos en marcha el centro con profesionales especialistas en el ámbito de la familia desde el modelo sistémico, muchas de ellas son profesoras en la Facultad. Fue un centro que funcionaba muy bien, era como un dulce porque era un tema muy difícil pero el equipo profesional lo supo hacer realmente bien porque era un equipo de profesionales de diez. Después de cuatro años nos tocaba renovar el convenio como en el caso anterior, después de citarnos con la consejera de turno en ese momento en la Comunidad de Madrid, nos pregunta que por qué estamos realizando las intervenciones desde la mirada sistémica. Le explicamos que viene recogida en las memorias que hemos ido haciendo cada año, donde además hemos ido contando reflexiones de cómo hacerlo, puntos de mejora, etc. Nos dice que no está de acuerdo con la orientación sistémica y que le salimos muy caros, y nos dice, un quince de diciembre, que no nos renueva el convenio. A treinta de diciembre tuvimos que cerrar el local, derivar los casos, despedir al equipo, etc. Se fue haciendo la transición y todavía me emociono cuando lo recuerdo, pero que no digan que si lo público, que si lo privado, lo que hay que hacer es conocer las reglas del juego y se debe convivir, siempre sabiendo que el control lo tiene la Administración pública, pero ofreciendo el mejor servicio. Nuestra vocación -la de INTRESS- no ha sido tener centros propios sino gestionar de la mejor manera posible centros públicos al servicio de la población destinataria.

Esto que cuentas enlaza con la siguiente pregunta que se refiere a la relación entre lo técnico y lo político en la intervención social. ¿Cómo han afectado a tu quehacer profesional las decisiones politicas? A veces las técnicas, las trabajadoras sociales, hablan de que son la cara visible de decisiones politicas con las que no siempre se sienten identificadas. Sería interesante conocer cómo ves tú la relación entre estas dos esferas.

Pues es que yo creo que la relación entre lo técnico y lo político es imprescindible; es decir, las profesionales, las técnicas que están ahí al filo de la acción, de la intervención, lógicamente aplican políticas que a veces no comparten, pero es que si no las compartes, lo que tienes que hacer es tratar de modificarlas. Aquí es donde hablo de la implicación de trabajadoras sociales en la política. Hubo un tiempo en que fue grande y eso se notó en la implantación de un sistema, creo que tiene impronta de trabajadoras sociales, y luego hubo un tiempo como de acomodación, bueno pues ya estamos aquí, ya nos podemos quedar tranquilas. Ya es- 
tamos y eso es la muerte porque entonces otros toman decisiones por ti y hacen planteamientos en los que tú no has tenido voz. Ahí te digo que yo no me he implicado en política, porque no se ha dado la situación. Pero el tiempo ese que te contaba de la Consejería tiene que ver con una opción política compartida con todo un grupo que estaba en el poder y ¿por qué era el poder? Pues quien tiene el poder tiene la decisión. Por lo tanto, tienes que querer estar allí porque no puedes estar quejándote todo el rato y no hacer nada. Por suerte hay compañeras que se han involucrado y que se ha notado o que se han peleado para hacerlo. A mí me parece que un trabajador social tiene como varios planos: uno, el de la acción directa, en el que por supuesto tienes que buscar la mejor formación, la mejor manera de poder hacerlo; pero a la vez, tiene el nivel de la planificación, el nivel de la propuesta, y tiene que ver con decisiones políticas y eso se hace entrando en lo que llamamos política o entrando en entidades, asociaciones, etc. que tienen el poder de influir en la política. Ahí los Colegios profesionales tienen un papel fundamental. Hay que pasar de la acción a la queja. Creo que tienes que buscar cuál es el resquicio para que se escuche tu voz que es tan digna como cualquier otra, y a veces las mujeres nos dejamos frenar.

Eso es muy interesante porque llama la atención que siendo una profesión femenina, a las mujeres en Trabajo Social nos cuesta mucho estar en puestos de decisión, en cargos con cierto poder. Y ya, para terminar, ¿qué retos consideras que tiene el Trabajo Social por delante? Soy consciente de que es una pregunta muy amplia, pero me refiero sobre todo a que nos aportes una reflexión después de tantos años de experiencia en la intervención social.

Fíjate que esta pregunta es la que más tiempo llevo pensando porque me parece que, actualmente, esta profesión está en un momento de dignidad profesional reconocida, pero to- davía le queda mucho camino por recorrer porque no siempre es reconocida socialmente. Académicamente ha llegado al máximo nivel con el grado, el máster y el doctorado, pero eso no significa que haya que quedarse allí, hay que aspirar a más. Por primera vez hay una decana mujer y trabajadora social en la Facultad de Trabajo Social de la Universidad Complutense de Madrid. Creo que tenemos que aspirar a tener cabida en esos espacios de decisión de los que hablábamos. Bueno... creo que vamos por el camino o eso pienso cuando salgo de la lectura de la tesis de Libertad, de Gónzalez Abad, Maribel Nebreda, de Maribel Estalayo, que no pude estar pero me he leído la tesis y disfruté muchísimo. Entonces cuando estoy en esos espacios, ¿qué pienso? Pues me da esperanza porque hay mujeres que están estudiando y diciendo cosas de la profesión muy importantes y muy interesantes. Al final tendrán sus espacios para decir lo que estudian del Trabajo Social: Son mujeres que no se han quedado en el papel asignado a la mujer que es un papel muy complicado quitárselo de encima. O sea veo que académicamente hay un nivel cada vez más alto y, sobre todo, más centrado en la profesión. Pero también creo que no podemos dejar de luchar porque aunque te diga que académicamente hay nivel, hace nada estábamos en que si desaparecíamos como Facultad, que si se quedaba. Yo recuerdo que os lo peleasteis estupendamente pero claro, esto es algo que se pelea y se va a seguir peleando, porque nadie nos ha regalado nunca nada. Creo que iremos hacia confluencias con otras profesiones, como por ejemplo las educadoras sociales, también creo que la existencia de grupos de reflexión y crítica sobre la situación social y la situación de la profesión nos harán evolucionar. Creo que nos va a ir bien porque cada vez hay mujeres mejor formadas y decididas a que se les respete su papel como profesionales. 